\title{
EN TORNO A LA PRESCRIPCIÓN EXTINTIVA
}

\author{
FERNANDO VIDAL RAMÍREZ*
}

\begin{abstract}
Resumen
El decurso del tiempo como fenómeno jurídico y, más concretamente, como hecho jurídico, tiene especial relevancia en cuanto que puede ser extintivo de una relación jurídica, ya porque dé lugar a la constitución de una nueva, como en la prescripción usucupativa; ya porque también puede extinguir la pretensión que deriva del derecho integrado a ella, como en la prescripción extintiva; o porque puede extinguir el derecho mismo, como en la caducidad.
\end{abstract}

Palabras clave: Usucapio - Prescripción usucupativa - Prescripción extintiva - Caducidad

\begin{abstract}
The course of time as a legal phenomenon and, more concretely, as a legal event, has special importance as it can extinguish a legal relationship either because it originates a new one, as in the case of usucapio or adverse possession; or it can also extinguish the claim deriving from the right inherent to it, as it is the case of negative prescription (lashes), or because it can extinguish the right itself, as it is the case of lapsing.
\end{abstract}

Key words: Usucapio - Adverse possession - Negative prescription (lashes) - Lapsing.

\section{Sumario}

1. Noción genérica de la prescripción. 2. Antecedentes históricos. 3. La prescripción en la codificación civil moderna. 4. La prescripción en la codificación civil peruana. 5. Prescripción usucupativa y prescripción extintiva. 6. Prescripción extintiva y caducidad.

\section{NOCIÓN GENÉRICA DE LA PRESCRIPCIÓN}

En una noción genérica, la prescripción se puede entender como un medio o modo por el cual, en ciertas condiciones, el decurso del tiempo modifica sustancialmente una relación jurídica.

\footnotetext{
* Miembro del Consejo Consultivo del Poder Judicial y Miembro de la Comisión Revisora del Código Civil.
} 
La prescripción, en esta noción genérica según la explica Ennecerus ${ }^{1}$, es el nacimiento y la terminación o desvirtuación de derechos en virtud de su ejercicio continuado o de su no ejercicio continuado y, en consecuencia, distingue la prescripción adquisitiva -que nosotros preferimos llamar usucupativa o simplemente usucapión - de la prescripción extintiva. Advierte el tratadista alemán que la prescripción no se configura de un modo uniforme para todas las relaciones jurídicas y que, por tanto, hay que prescindir de una doctrina general de la prescripción, aunque algunas de sus manifestaciones concretas se repitan en las distintas clases de prescripción.

La opinión de Ennecerus, que resume la de la doctrina alemana, representa una corriente doctrinal muy acentuada en cuanto a un desarrollo dual de la prescripción: de un lado, la adquisitiva o usucupativa y, de otro, la extintiva o liberatoria. Así, dentro de esta corriente doctrinal ambas clases de prescripción tienen en común que se fundan en el transcurso del tiempo, pese al razonamiento atribuido a Giorgi en el sentido de que nadie puede conquistar un derecho si no es a expensas de quien lo pierde, por lo que la prescripción sería adquisitiva y extintiva al mismo tiempo.

Así planteado el dilema frente a la prescripción, legislación y doctrina peruanas han optado por la diferenciación de las dos clases de prescripción, desde que cada una constituye un instituto jurídico distinto, con sus propias características, aun cuando puedan tener como sustento común el transcurso del tiempo y que ambas sean instituciones jurídicas que se fundamentan en consideraciones de orden público.

El decurso del tiempo es, pues, el que produce los efectos jurídicos necesarios para que operen tanto la prescripción adquisitiva como la prescripción extintiva. Por la primera, el simple poseedor de un bien puede devenir en propietario y, por la segunda, el titular de un derecho no podrá ejercitar útilmente la acción que le es correlativa para hacer efectiva su pretensión.

\section{ANTECEDENTES HISTÓRICOS}

Los antecedentes históricos de la prescripción se remontan al derecho romano, que le dio el perfil de institución jurídica, habiendo, en el tiempo, precedido la prescripción usucupativa a la prescripción extintiva.

La usucapio (de usu capear: adquirir por el uso), según Petit ${ }^{2}$, apareció en Roma como un modo de adquirir la propiedad de las cosas por una posesión suficientemente prolongada, siendo necesario para usucapir, apoderarse de una 
cosa y hacer uso de ella. La inacción prolongada del propietario equivalía al abandono tácito de su derecho y, al cabo de un tiempo, la adquisición quedaba consumada en beneficio del poseedor. El peligro que significaba ese modo de adquirir lo limitó la Ley de las XII Tablas, que prohibió la usucapión de las cosas robadas, introduciendo la idea del justo título y de la buena fe en la posesión. Mucho tiempo después, según el propio Petit, luego de haberse fijado por los jurisconsultos romanos las condiciones necesarias para la usucapión, apareció otra institución destinada a proteger a los poseedores de fundos, para los cuales no se aplicaba la usucapión, y que era la praescriptio longi temporis.

La gran obra de Justiniano, que resumió las instituciones jurídicas romanas en el Corpus Iuris Civilis, fusionó la praescriptio longi temporis con la usucapio, siendo así receptada por la codificación civil moderna.

\section{LA PRESCRIPCIÓN EN LA CODIFICACIÓN CIVIL MODERNA}

Con los remotos antecedentes que han quedado expuestos, la prescripción fue receptada, básica y fundamentalmente, por la codificación civil. Así, en 1804 el Código francés la legisló en sus dos modalidades, como usucapión y como prescripción extintiva, estableciendo que "la prescripción es un modo de adquirir o de liberarse por transcurrir un espacio de tiempo en las condiciones determinadas por la ley" (artículo 2219), para luego desarrollar un tratamiento unitario, tanto en lo atinente a la prescripción adquisitiva como en lo correspondiente a la prescripción extintiva.

El tratamiento que el Código de Napoleón dispensó a la prescripción influyó en los Códigos del siglo XIX y es así como, entre otros, los Códigos chileno, colombiano, argentino, de Costa Rica y de España, aún vigentes, por ejemplo, regularon la prescripción adquisitiva y la prescripción extintiva como si fueran los aspectos de una sola institución jurídica. El Código Civil de 1852, también bajo la influencia del Code Civil, le dio este tratamiento.

Considerando inconveniente el tratamiento legislativo unitario, la doctrina comenzó a formular el planteamiento dual impulsado por la doctrina alemana y que ha sido seguido por la codificación civil a partir de 1900, fundándose en que, aparte del elemento fáctico del transcurso del tiempo, los requisitos exigibles para una y otra prescripción son distintos. Según anota De Gasperi ${ }^{3}$, razón tuvo Savigny al impugnar por falsas las expresiones adquisitiva y extintiva, pues, en su opinión, no había una prescripción construida con reglas sencillas, por lo que propugnó la doctrina que concluye en que no puede haber una teoría general de la prescripción aplicable a todas las 
relaciones jurídicas y a los derechos que emergen de ellas, fueran absolutos o relativos.

Acogiendo las ideas de Savigny, el Código alemán, vigente desde 1900, legisló por separado la usucapión, como un modo de adquisición de la propiedad de las cosas, y, la prescripción, como un modo de extinción de las pretensiones. Similar tratamiento le dieron a la prescripción el Código brasileño de 1917 - de gran influencia en el Código Civil peruano de 1936 - , el Código italiano, el Código boliviano y el Código paraguayo, así como el vigente Código Civil peruano, al legislar sobre la usucapión como un modo de adquirir la propiedad o como un efecto de la posesión, y, separadamente, sobre la prescripción extintiva, siendo éste el tratamiento que recibe en la codificación contemporánea, pese a que Códigos del siglo XX como el mexicano para el Distrito Federal y el venezolano han mantenido el tratamiento unitario. El Código brasileño que ha venido a derogar al de 1917 mantiene el tratamiento dual de la prescripción.

Paralelamente a la codificación civil, la codificación mercantil comenzó también a legislar sobre la prescripción, aunque, obviamente, sólo sobre la extintiva y sin introducir una normatividad sistemática y completa mas allá de precisar características muy propias, pero dejando su tratamiento y desarrollo, básicamente, a la codificación civil, por lo que nunca se ha desarrollado una doctrina de la prescripción distinta a la desarrollada por la doctrina civilista. La desmembración de la codificación mercantil ha traído como consecuencia que las leyes especiales en las que se ha ido desmembrando legislen sobre la prescripción extintiva.

\section{LA PRESCRIPCIÓN EN LA CODIFICACIÓN CIVIL PERUANA}

El Código Civil de 1852, como los demás Códigos del siglo XIX, como ya hemos advertido, no pudo sustraerse a la influencia del Código napoleónico y dio a la prescripción el mismo tratamiento al desarrollar de manera unitaria tanto la que denominó de dominio (usucupativa) como la de acciones (extintiva).

El Código de Comercio de 1902, que adaptó a nuestro medio el Código de Comercio Español de 1885, obviamente legisló sólo sobre la prescripción extintiva.

El Código Civil de 1936 acogió criterio distinto al de 1852 y, siguiendo la corriente doctrinal impuesta por los pandectistas alemanes que trazaron la distinción que se adoptó en el BGB y que se reflejó en el Código brasileño 
de 1917, legisló por separado la prescripción adquisitiva o usucupativa y la prescripción extintiva. De este modo, llevó la prescripción adquisitiva al Libro Cuarto dedicado a los Derechos Reales, legislando separadamente la usucapión inmobiliaria de la mobiliaria, y, la prescripción extintiva al Libro Quinto dedicado al Derecho de las Obligaciones, aunque sin hacer una radical desvinculación, ya que, según su artículo $876^{\circ}$, "rigen en esta prescripción (la adquisitiva), las reglas establecidas para la extintiva en cuanto sean aplicables". Esta disposición fue calificada por Jorge Eugenio Castañeda ${ }^{4}$ como "ilógica e incongruente, si se acepta que la prescripción adquisitiva y la extintiva son instituciones disímiles, pues así parece haberlo entendido el legislador cuando las instaló en diferentes Libros".

Planteada la reforma del Código Civil de 1936, como ponentes que fuimos ante la Comisión Reformadora, propugnamos el mantenimiento del tratamiento dual de la prescripción a fin de que la prescripción adquisitiva continuara tratada en el Libro de los Derechos Reales, por ser este instituto un modo de adquirir la propiedad de los bienes y constitutivo de derechos reales, y que la prescripción extintiva se llevara a un Libro especial y no se le mantuviera ligada al Libro de las Obligaciones. Indicamos que el transcurso del tiempo, que es el sustento de ambas clases de prescripción, en la usucupativa produce un efecto erga omnes en favor del prescribiente, lo que no ocurre en la extintiva, que libera al prescribiente únicamente respecto del sujeto con quien tenía entablada una relación jurídica particular, a lo que debemos precisar ahora, atendiendo a la posición asumida por el Código Civil, que no se trata de liberarlo del cumplimiento de una prestación sino de reconocerle la posibilidad de oponer la prescripción frente a la pretensión que contra él se quisiera hacer valer. Concluimos en que tan sustancial diferencia eximía de mayor abundamiento para justificar el mantenimiento del trato legislativo del Código Civil de 1936, aunque, como hemos indicado, no solo sustrayendo la prescripción extintiva del Libro de las Obligaciones, sino instalándola en un Libro especial ${ }^{5}$.

El Código Civil vigente desde el 14 de noviembre de 1984 llevó, pues, a la prescripción extintiva a un Libro especial - el Libro VIII - que legisla también sobre la caducidad. A la prescripción adquisitiva, tanto mobiliaria como inmobiliaria, la legisla al hacerlo sobre los modos de adquisición de la propiedad (artículos $950^{\circ}$ y $953^{\circ}$ ) y sin reproducir la norma del artículo $876^{\circ}$ del Código anterior. Según el artículo $950^{\circ}$, la propiedad inmueble se adquiere por prescripción mediante la posesión continua, pacífica y pública como propietario durante diez años y, a los cinco años, cuando median justo título y buena fe. Por el artículo $951^{\circ}$, la adquisición por prescripción de un bien 
mueble requiere la posesión continua, pacífica y pública como propietario durante dos años si hay buena fe, y por cuatro si no la hay. El artículo $952^{\circ}$ faculta al prescribiente a entablar juicio para que se le declare propietario, indicando que la sentencia es título para la inscripción de la propiedad en el Registro de la Propiedad Inmueble y para cancelar el asiento en favor del antiguo dueño. Por último, el artículo $953^{\circ}$ - reiterando el texto del artículo $875^{\circ}$ del derogado Código de 1936 - mantiene como causal de interrupción del decurso prescriptorio la pérdida o la privación de la posesión, salvo que se recupere antes de un año o si por sentencia se restituye.

Como excepción al principio que regula las normas que hemos dejado expuestas y a la doctrina que las informa, el Código Civil legisla también sobre la pérdida de derechos reales por el no uso. Se trata de la extinción del usufructo por el no uso del usufructuario durante cinco años, conforme al inciso 2 del artículo $1021^{\circ}$, y de la extinción de las servidumbres, también por el no uso durante cinco años, conforme al artículo $1050^{\circ}$. En ambos casos, la prescripción es usucupativa y no extintiva porque no es una praescriptium actionem, pues opera en favor del titular del derecho sobre la cosa fructífera y del titular del derecho sobre el predio sirviente, respectivamente.

Por último, la regulación del arbitraje, materia desprendida del Código Civil vigente, en la actualidad sometida a la Ley N²6572, Ley General de Arbitraje, ha introducido también normas sobre prescripción extintiva, que se suman a las de otras leyes especiales.

\section{PRESCRIPCION USUCUPATIVA Y PRESCRIPCION EXTINTIVA}

Considerando el tratamiento dual que a partir de 1936 la codificación civil peruana viene dando a la prescripción, es conveniente establecer el fundamento doctrinal de la separación de la prescripción usucupativa de la prescripción extintiva.

Contra la posición sostenida por la doctrina unitarista, que estima a la prescripción como la transformación reconocida por la ley de una situación de hecho en una situación de derecho por el transcurso del tiempo, la doctrina dualista sostiene que si bien tal transformación se produce en la prescripción adquisitiva, salvo el caso que opere por el no uso, no ocurre lo mismo con la prescripción extintiva, porque en esta lo que se desvanece es la situación jurídica como consecuencia del no ejercicio de la correspondiente acción protectora del derecho. 
El transcurso del tiempo, según escribió León Barandiarán ${ }^{6}$ en sus comentarios al Código Civil peruano de 1936, puede tener un efecto decisivo en cuanto a las recíprocas situaciones del titular de un derecho frente al sujeto pasivo del mismo dentro de la órbita de la prescripción extintiva, puesto que el resultado que sobreviene es la modificación de la situación entre los dos sujetos, en razón de que uno de ellos puede liberarse ante el accionar del otro oponiéndole, precisamente, la prescripción extintiva. En la prescripción usucupativa, por el contrario, se crea una modificación en la posición jurídica del usucapiente que no solo atañe al anterior propietario, contra el cual la prescripción adquisitiva se produce, sino erga omnes, porque se ha constituido un derecho real en favor del prescribiente.

La doctrina que distingue la usucapión de la prescripción, encuentra, pues, fundamentos de diversa índole para justificar y explicar el tratamiento diferenciado. Así, atendiéndose a los requisitos para prescribir, en la adquisitiva se requiere, como factor determinante, de la posesión del usucapiente, que es un hecho positivo; mientras que en la prescripción extintiva se requiere, también como factor determinante, de la inacción del titular del derecho que está en la posibilidad de accionar, que es un hecho negativo. Por el ámbito de aplicabilidad de la prescripción, la adquisitiva solo es susceptible de aplicarse a los derechos reales que pueden ser materia de posesión, mientras que la extintiva se aplica no solo a los derechos reales, sino también a los creditorios, y en general, a los de naturaleza patrimonial. Por los efectos de la prescripción, en la usucupativa los efectos son adquisitivos y extintivos, pues los derechos los adquiere el usucapiente y los pierde el anterior titular del derecho; mientras que en la extintiva, los efectos son meramente extintivos, porque solo liberan al deudor de la acción del acreedor para hacer efectiva su pretensión y le dan un medio de defensa que oponerle.

Por último, es del caso destacar que el tratamiento dual de la prescripción no permite determinar una sola naturaleza jurídica, como tampoco, es obvio, un concepto único de ella. Siendo un vocablo anfibológico, solo la dualidad permite su explicación: de un lado, como prescripción adquisitiva y, de otro, como prescripción extintiva.

\section{PRESCRIPCIÓN EXTINTIVA Y CADUCIDAD}

El decurso del tiempo dota de afinidad a la prescripción extintiva y a la caducidad, lo que determina una relativa confusión. Sin embargo, la doctrina ha establecido la diferenciación que ha sido acogida por el Código Civil peruano. 
En efecto, el Código Civil las diferencia con nitidez, pese a las confusiones que ofrecen, pues para la prescripción extintiva se extingue la acción, que debe interpretarse como la pretensión, mas no el derecho (artículo $1989^{\circ}$ ), mientras que para la caducidad se extingue el derecho y la acción correspondiente (artículo $2003^{\circ}$ ), ya no entendida como pretensión sino como el derecho de acción, esto es, como derecho a la jurisdicción.

\footnotetext{
Ennecerus. Tratado de Derecho Civil. T. I. Parte General III. Vol. 2, pp. 1009-1010.

Petit. Tratado Elemental de Derecho Romano. p. 206.

De Gasperi. Tratado de Derecho Civil. III, p. 382.

Castañeda, Jorge E. Instituciones de Derecho Civil. Los Derechos Reales. T.I, p. 242.

5 Proyectos y Anteproyectos de la Reforma del Código Civil. T.II, pp. 695-696.

6 León Barandiarán, J. Tratado de Derecho Civil. T. VIII, pp. 80-81.
} 